\title{
The Coordinated Individual Plan - is this a solution for complex organizations to handle complex needs?
}

\author{
David Matscheck, Katarina Piuva, Lisbeth Eriksson \& Martin Åberg
}

To cite this article: David Matscheck, Katarina Piuva, Lisbeth Eriksson \& Martin Åberg (2018): The Coordinated Individual Plan - is this a solution for complex organizations to handle complex needs?, Nordic Social Work Research

To link to this article: https://doi.org/10.1080/2156857X.2018.1489886

Published online: 04 Aug 2018.

Submit your article to this journal $\sqsubset$

View Crossmark data ¿ 


\title{
The Coordinated Individual Plan - is this a solution for complex organizations to handle complex needs?
}

\author{
David Matscheck ${ }^{\mathrm{a}, \mathrm{b}}$, Katarina Piuva ${ }^{\mathrm{b}}$, Lisbeth Eriksson ${ }^{\mathrm{c}}$ and Martin Åberg ${ }^{\mathrm{d}}$ \\ ${ }^{a}$ FoU Nordost [RD Northeast], Danderyd, Sweden; bepartment of Social Work, Stockholm University, Stockholm, \\ Sweden; 'Division of Social Work and Pedagogy, Department of Social and Behavioral Studies, University West, \\ Trollhättan, Sweden; ${ }^{\mathrm{d} F o U}$-Nordväst [RD Northwest], Sollentuna, Sweden
}

\begin{abstract}
Persons with mental health problems and substance abuse often have complex needs requiring many kinds of help concurrently. In Sweden, an attempt has been made to counterbalance the effects of fragmentation by means of legislation on collaboration, requiring on the individual level the use of Coordinated Individual Plans (Sw. Samordnad Individuell Plan, SIP). The aim of the study is to explore collaboration as it is indicated in SIP and other case documentation with focus on how SIP is motivated, and what kind and degree of collaboration is indicated by the documentation. 12 individual case files have been studied in six local authorities and the results have been analyzed in relation to a regional collaboration agreement and local collaboration agreements. The results show unclear motivation for SIP and that SIP is primarily used for documentation of short-term planning. Use of SIP and participation in SIP appears also to be uneven. The authors characterize SIP as an unsystematic form of interagency meeting, with documentation indicating a relatively low to moderate level of collaboration. The authors question whether SIP is an optimal form for collaboration and suggest that more distinct models such as case management or multidisciplinary teams could be more effective.
\end{abstract}

Abbreviation SIP: Coordinated Individual Plan (Sw. Samordnad Individuell Plan)

\section{KEYWORDS}

Coordinated Individual Plan; collaboration; complex needs; mental health; integrated care

\section{Introduction}

Collaboration between service providers for mental health problems and alcohol and drug abuse has been increasingly discussed in recent years. Individuals with problems in these areas have need of many kinds of help concurrently, such as psychosocial interventions, specialized medical care, housing, personal economy and work-related rehabilitation. People with problems in both areas - characterized as 'complex needs', 'double diagnosis' or 'co-occurring severe mental health and substance use disorders' - are particularly affected. A summary of international research shows that as many as $50 \%$ of individuals with severe mental disorders are affected by substance abuse and that double diagnosis is associated with negative outcomes such as high rates of relapse, hospitalization, incarceration and homelessness (Drake et al. 2001). Research especially emphasizes the importance of integrated social and medical care. But instead, these persons are met by separate systems of help and treatment which deliver fragmented and ineffective care. They are often excluded from services in one system and told to return when the other problem is under control (Horsfall et al. 2009). 
These difficulties are among the consequences of a fundamental characteristic of the modern welfare state, which has developed through a process of specialization and differentiation (Axelsson and Bihari Axelsson 2006). The effects can be observed in the division of services into sectors, organizations and professions, often with inflexible boundaries (Sullivan and Skelcher 2002; Miller and Ahmad 2000). In sum, the more complex the individual's problems, the more fragmented the service and the more difficult for the person to get coordinated help for his or her total situation.

An additional factor is steering by principles of New Public Management (NPM), which aims to increase efficiency in the public sector by means of greater use of business techniques, often including increased marketization (Hood 1991; Shanks, Lundström, and Wiklund 2015). NPM divides services into purchaser and provider units, sometimes in combination with customer choice models, thereby multiplying the number of organizational units involved both on the organizational and individual case level.

In Sweden, help for persons with mental health and substance abuse problems involves social services provided by local authorities (or 'municipalities'), health care provided by regional authorities (county councils, Swedish 'landsting') and social insurance by the state. The responsibility for housing and economic assistance lies with the local authorities, while responsibility for work rehabilitation and employment lies primarily with the state (Melke 2010), though in the case of the latter shared with the local authorities' social service. The state is responsible for correctional services, which have responsibility for rehabilitation for persons who have been convicted of certain crimes. The organizational landscape is illustrated by the figure below (Figure 1).

The latest attempt to address the problems presented by sectorization and fragmentation in Sweden was introduced in 2009, when legislation was passed requiring local collaboration agreements and the 'Coordinated Individual Plan' (Sw. Samordnad Individuell Plan, SIP). A 'SIP' is required when it is judged by the professionals concerned that an individual user has need of interventions or care from both the local authority's social service and the county council's health care sector, and when the individual agrees to the plan. The plan shall include 1) what interventions are needed, 2) which authority or care unit is responsible for which intervention, 3) what measures are taken by other parts and 4) which authority or care unit is responsible for the plan (SFS 2001:453, amended SFS 2009:981). The plan

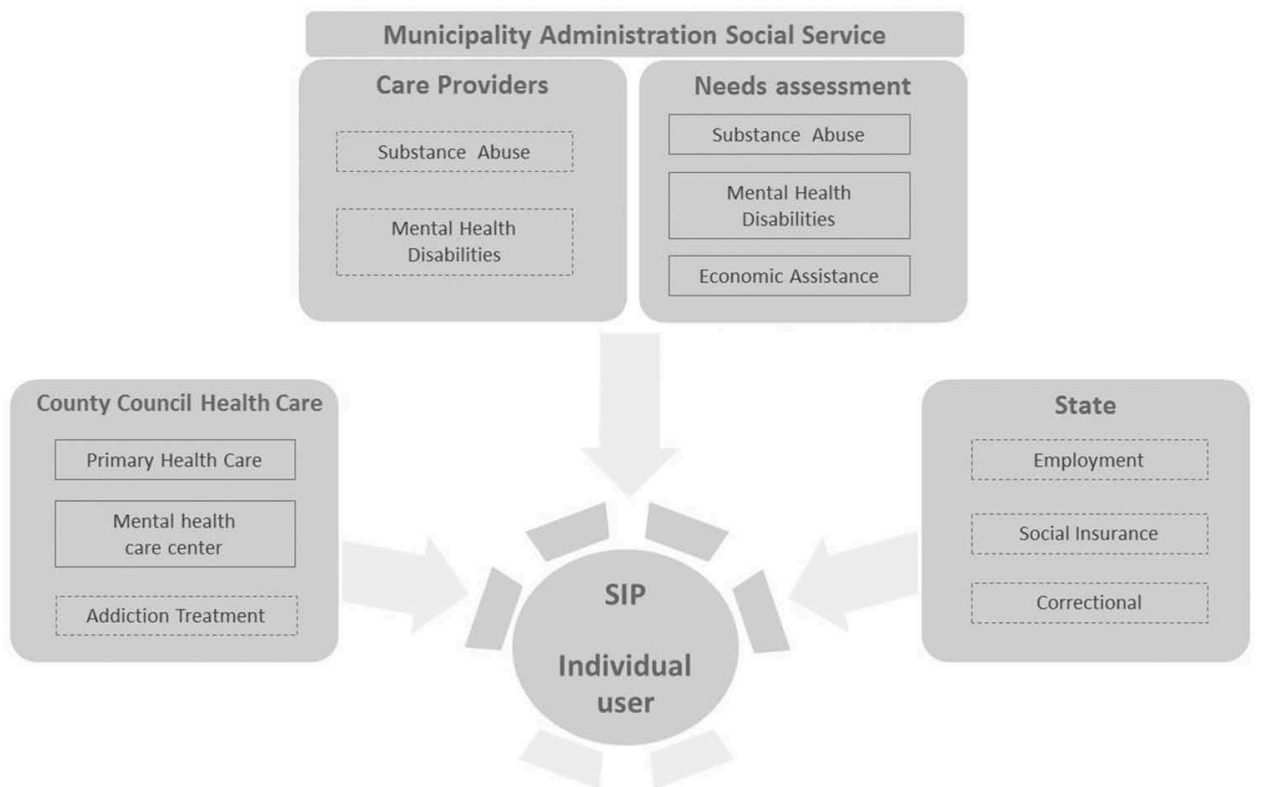

Figure 1. Sectors and organizations with responsibility for service for adults with mental health problems and substance abuse in Sweden. 
is to when possible be drawn up 'together with' the individual user and the user shall 'participate actively' (Governmental Proposition 2008/09:193, 24).

The politically expressed purpose of the 'SIP' is to 1) Increase user involvement and influence in their own care, 2) Ensure that the individual user receives the help he/she is entitled to, 3) Clarify questions of responsibility between principals and improve the total care process, and 4) Improve quality of service (Governmental Proposition 2008/09:193). Unlike the collaboration forms recommended by national guidelines (National Board of Health and Welfare 2011,2015), local collaboration agreements and SIP carry the force of law, through identical paragraphs in the Social Service Act (SFS 2001:453, amended 2009:981) and the Health and Medical Care Services Act (SFS 1982:763, amended 2009:979). Economic incentives have also been used to stimulate implementation of local agreements and 'SIP'.

\section{Aim}

This study aims to explore collaboration in individual cases as it is indicated in coordinated plans (SIP documents) and other case documentation with regard to the target group. The study has been guided by the following research questions:

- How is collaboration motivated, in other words, why collaborate?

- What kind of collaboration and what degree of collaboration is indicated by the SIP documents and other individual case documentation?

The study is explorative and the authors hope that the results can contribute to a deeper understanding of the role of SIP in collaboration.

\section{Theoretical perspectives on collaboration}

Collaboration is usually used as an overall concept for an organizational area also involving the related concepts 'coordination' and 'cooperation'. These concepts are used in the legislation on collaboration agreements and SIP, although the definitions and intended meaning of the concepts is not always clear. Andersson and colleagues (2011) have identified seven basic models of collaboration, which they have arranged according the following scale (simplest to most complex): 'Information exchange', 'case coordination', 'interagency meetings', 'multidisciplinary teams', 'partnership', 'co-location' and 'pooled budgets'.

Axelsson and Bihari Axelsson (2006) analyze collaboration based on concepts of organizational integration from contingency theory as defined by Lawrence and Lorsch (1967). According to contingency theory, increased differentiation (or specialization) between organizations and functions leads to a greater need for organizational integration. Lawrence and Lorsch define organizational integration as 'the quality of the state of collaboration that exists among departments that are required to achieve unity of effort by the demands of the environment' (Lawrence and Lorsch 1967, 11). Axelsson and Bihari Axelsson (2006) interpret this definition to apply to integration between different organizations and sectors, which is a definition appropriate to this study.

Axelsson and Bihari Axelsson also provide a conceptual model for understanding collaboration as a form of organizational integration (Axelsson and Bihari Axelsson 2006). The model involves a vertical axel within each organization and a horizontal axel between corresponding levels of the organizations involved. The vertical axel follows the organizational hierarchy, from higher management to front-level operations. Specialization of departments and organizational units occurs along this axel. Contacts which are mainly on the vertical axel can be characterized as coordination, rather than actual collaboration, and involve, for example, parallel operations rather than integrated operations. Integration on the horizontal axel often takes the form of informal 

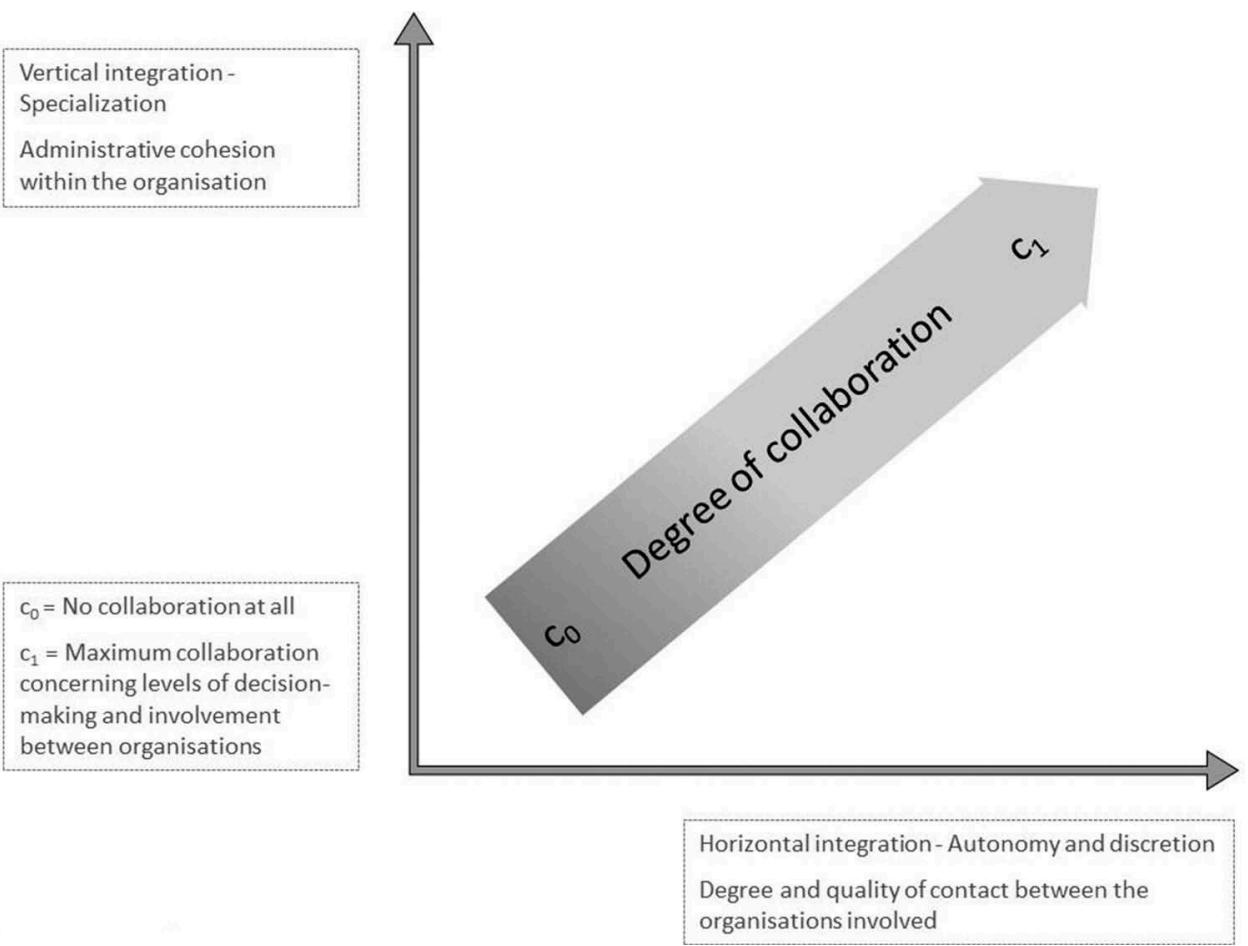

Figure 2. Model for analysis of collaboration structure (adapted from Axelsson and Bihari Axelsson 2006).

cooperation in front-level operations, where it has to do with the degree of autonomy for individual professionals and room for discretion in individual cases. Organizational forms such as multidisciplinary teams can also be created along the horizontal axel. Figure 2 below shows an interpretation of Axelsson and Bihari Axelsson's conceptual model, as adapted by the authors.

\section{Research on collaboration and individual plans}

Collaboration has internationally become an extensive area for research (see for example Sullivan and Skelcher 2002; Miller and Ahmad 2000; Andersson et al. 2011). Research more specifically concerning the target group for this study has mainly focused on integrated models for treatment and support, such as case management or multidisciplinary teams (see for example Drake et al. 2001). Horsfall and colleagues (2009) have shown that integrated models can be important in helping individual treatments to be effective. In Sweden, Lindberg and Wikström (2013) have analysed the problems in care and support for persons with substance abuse which can occur when collaboration is implemented in the form of timelimited projects.

A few recent studies have focused specifically on coordinated individual plans, SIP. In a local evaluation, Ekendahl and Karlsson (2013) found that users were often unclear about which authorities were responsible for which needs. A regional evaluation (Winquist 2016), concerning use of SIP with both adults and with children or families, found that professionals and users were positive to SIP, but that implementation was uneven. Källmén and Elgán (2016), in a survey evaluation concerning adults with mental health problems and substance abuse, also found uneven use of SIP. 


\section{Method}

\section{Setting and local conditions}

There are 26 local authorities in the Stockholm region, all of which belong to a branch organization, the Stockholm Association of Local Authorities. The corresponding regional organization responsible for health care is the Stockholm County Council. Since 2008, the Association of Local Authorities and the Stockholm County Council have an overarching collaboration agreement in the area of substance abuse. In 2012, the regional agreement was expanded to include mental health. The regional agreement establishes an overall structure for collaboration, as a way of coordinating the local agreements which are required by law (Matscheck and Fleetwood 2013). The regional organizations have also prepared a manual which recommends that SIP be prepared in consultation with the user (Stockholm Association of Local Authorities (KSL) and Stockholm County Council (SLL) 2014).

The authors have studied SIP in six local authorities in the Stockholm region, examining collaboration agreements and individual case files. The local authorities vary in size and character, from about 25000 to 75000 in population and from urban to countryside. All six have a purchaser-provider organization, with a section for assessment and follow-up, and either separate units for service provision or contracts with private providers. At the time of the study, all six had signed the regional collaboration agreement (Matscheck and Fleetwood 2013).

The regional collaboration agreement created a collaboration structure involving a regional 'coordinating council' and local coordinating councils with representatives from the social service, local clinics for addiction treatment and mental health and the probation division of the correctional services. ${ }^{1}$ Five of the local authorities had current local agreements with collaboration partners in the health care sector, while the sixth local authority referred to the regional agreement. Four local agreements included the social service's substance abuse and mental health units and their corresponding units for service provision, and the county council's local clinics for addiction treatment, psychiatric care and primary health care. Two agreements were also signed by the probationary division of the correctional services and one by the state social insurance agency. One agreement included only the social service's mental health unit and the local psychiatric out-patient clinic.

In accordance with the regional agreement, the local agreements all had a structure involving a local coordinating council for overarching issues. Representatives in the local coordinating council were usually second-tier managers ${ }^{2}$ for the respective units. The local agreements also established work-groups for front-line managers and provisions for SIP as a means of handling individual cases.

\section{Data selection}

Individual case documentation is usually written relatively soon after the events have taken place. For this reason, studying case files can be a way of coming closer to events than is possible in, for example, surveys or interviews, and thereby achieve greater validity (Merriam 1988). The results can also lay groundwork for coming studies. A limitation is that cases files are a social construction adapted to an administrative process, in which a professional person documents what he or she judges to be important for the immediate purpose. The documentation can therefore not be regarded as a balanced account (Billquist and Johansson 2007). Nevertheless, case files have the advantage of being a stable source of data with a high level of authenticity and credibility (Scott 1990).

The authors have examined 12 individual case files. The social service sections for assessment and follow-up were responsible for the case files in the study. Two files were selected from each local authority, all concerning persons between 18 och 65 years of age. The criteria were that the files contain at least one SIP, and that one file include the last SIP done before 30 June 2014 and the other the last SIP before 30 June 2015. The purpose of the second criterium was to find a clear and stable data selection over a limited period of time. The study was approved by the Regional Ethical Review Board in Stockholm (Reg. Nr. 2015/441-31/5). 


\section{Model of investigation}

The regional collaboration agreement and the local agreements were examined for key formulations concerning aims and how collaboration was motivated and providing a background for the main focus of the study, the individual SIPs.

The regional health care services in Stockholm County used a standard form for SIP, with boxes for specific questions. This form was used for nearly all the SIPs in the study. But the authors expected, and the evaluations confirmed, that the SIP documents themselves would not contain enough information to answer the research questions. It was necessary to study the entire file, including investigations and assessments, care orders to service providers, journal entries and correspondence. In particular, background information on social situation and what interventions or other help the person already was receiving could be found in other documentation. Follow-up of SIP was also sometimes documented only in journal entries. Initially, to get a picture of which persons received SIPs, the following data was compiled: Age, sex, marital status, whether born in Sweden, mental health problems, substance abuse problems, physical health problems, employment, type of residence and other social circumstances. In addition, data was compiled concerning what help and interventions these persons received before the SIP.

Further, a protocol was designed to answer the study's research questions according to the following subqueries:

\section{How was collaboration motivated in the individual case files?}

- Was there an explicit motivation for the SIP?

- If the SIP was not explicitly motivated, what appeared to be the reason for the SIP?

- How were the needs and problems formulated?

- What actions and interventions were agreed upon?

- What goals were agreed upon for the SIP?

\section{What kind of collaboration and what degree of collaboration is indicated by the documentation?}

- Who initiated SIP?

- Which organizations (social service units, health care services and other agencies) participated in the SIP?

- How often were the SIPs updated?

- How active were the users according to the documentation?

- Which professionals (level of leadership and autonomy) represented the agencies and services which participated in SIP?

\section{Model of analysis}

To analyze how SIP was motivated, formulations in the collaboration agreements and in the case files (including the individual SIPs) have been examined.

To analyze what kind of collaboration is indicated, the data was analyzed using Andersson et al. (2011) scale for models of collaboration (see above). To analyze what degree of collaboration is indicated, the authors have adapted Axelsson and Bihari Axelsson's (2006) conceptual model (Figure 2). Use of SIP on the horizontal axel, based on the data compiled according to questions above, was analyzed in relation to the support provided by collaboration agreements.

\section{Findings}

Eight of the files studied belonged to the social service's sections for assessment of cases concerning substance abuse, three to sections for assessment of cases concerning mental health, 
and one (regarding a young person with substance abuse problems who had recently turned 18) to a section for assessment of cases concerning children and young people.

\section{What was documented in the sips and case files}

Bakground information on the needs and social situation for the individuals was often found in assessments or journal entries, rather than in the SIP. All 12 users had, in some respect, complex problems and needs. Most had substance abuse in combination with some form of mental health problem. Psychosis, bipolar syndrome or depression, autism spektrum disorder and ADHD were the most usual mental health problems, sometimes in combination. Problems with physical health ranged from hepatitus to knee or hip problems. One of the 12 individuals had regular employment, while seven had no form of work or regular activity. Four owned or rented regular housing, five had social housing, two lived with family and one was homeless. Seven had other social problems such as crime or prostitution. (Table 1)

\section{How was collaboration motivated in the individual case files?}

The individual SIPs were in general not directly motivated at all. Other formulations, either in the SIP or in journal entries, sometimes revealed changes in the person's circumstances, or simply that the individual already had contact with both or several parts and it seemed reasonable that they should meet.

Table 1. Summary of files/users in study.

\begin{tabular}{|c|c|c|}
\hline Category/problem & & Total \\
\hline \multicolumn{3}{|l|}{ Sex } \\
\hline Female & 7 & \\
\hline Male & 5 & 12 \\
\hline \multicolumn{3}{|l|}{ Marital status } \\
\hline Single & 11 & \\
\hline Married/couple & 1 & 12 \\
\hline \multicolumn{3}{|l|}{ Born in Sweden } \\
\hline Yes & 7 & \\
\hline No & 2 & \\
\hline Not documented & 3 & 12 \\
\hline \multicolumn{3}{|l|}{ Substance abuse problems } \\
\hline Alcohol & 2 & \\
\hline Narcotics & 10 & \\
\hline Farmaceuticals & 4 & 12 \\
\hline \multicolumn{3}{|l|}{ Mental health problems } \\
\hline Yes & 10 & \\
\hline No & 2 & 12 \\
\hline \multicolumn{3}{|l|}{ Physical health problems } \\
\hline Yes & 6 & \\
\hline No & 6 & 12 \\
\hline \multicolumn{3}{|l|}{ Employment } \\
\hline Full or part-time employment & 1 & \\
\hline Occupational training & 2 & \\
\hline Daily activities (social service) & 2 & \\
\hline None & 7 & 12 \\
\hline \multicolumn{3}{|l|}{ Residence } \\
\hline Regular housing (own or rental) & 4 & \\
\hline With parents or other family & 2 & \\
\hline Social housing & 5 & \\
\hline Homeless & 1 & 12 \\
\hline \multicolumn{3}{|l|}{ 0ther social problems } \\
\hline (Crime, prostitution) & & \\
\hline Yes & 7 & \\
\hline No & 5 & 12 \\
\hline
\end{tabular}


The aim of the SIP was usually formulated as a list of needs, or as a general formulation such as 'to be free from drugs'. It was not possible in any of the SIPs for the researchers to distinguish between immediate goals and interventions, as opposed to more long-term goals and planning. Most individuals already received some form of help and nine of the 12 already had parallell interventions from both the social service and either specialized addiction treatment or psychiatric care. According to the SIPs, all of the individuals were to receive some form of assistance. In most cases the interventions agreed upon meant some kind of change or addition to the already existing help. There were no SIPs which resulted in interventions by both addiction treatment and mental health care. Follow-up SIP-meetings or other documentation in the files showed that most of the planned interventions were wholly or partially implemented. (Table 2)

Journal entries suggest that many new interventions were planned already before the SIPmeeting or had actually been started, such as in connection with a move from residential care to a training apartment.

\section{What degree of collaboration is indicated by the SIP and other documentation?}

Four SIPs were initiated by the social service, in every case by a section for assessment and followup. Six were initiated by the health care sector, four of which by addiction treatment and two by out-patient health care. (Table 3 )

In every SIP, the social service was represented by a social welfare secretary. The local authorities all had separate units for assessment of substance abuse and mental health assistance, but both were seldom represented in the same SIP. Representation from the social service's care and support units was less usual, whether operated within the social service or by private contract. There were cases in which only the social welfare secretary for substance abuse assessment and a nurse from addiction treatment were present at the meeting and there were also cases in which only the social welfare secretary for mental health and a psychiatric nurse were present. From the health care sector, all representation was from care providers, which is in accordance with the way in which the purchaser-provider split has been implemented by the county council. There were

Table 2. Help, care and support before and after SIP.

\begin{tabular}{|c|c|c|c|}
\hline & Before SIP & After SIP & Total help** \\
\hline \multicolumn{4}{|l|}{ Social service } \\
\hline Substance abuse & 7 & 8 & \\
\hline Mental health & 5 & 4 & \\
\hline Economic assistance & 2 & 2 & \\
\hline Other social service ${ }^{* *}$ & 0 & 5 & \\
\hline Total with help from social service & 10 & 12 & \\
\hline \multicolumn{4}{|l|}{ Health care } \\
\hline Addiction treatment & 6 & 7 & \\
\hline Outpatient psychiatric care & 4 & 5 & \\
\hline Inpatient psychiatric care & 1 & 0 & \\
\hline Primary care & 1 & 1 & \\
\hline Total with health care intervention * & 9 & 13 & \\
\hline \multicolumn{4}{|l|}{ Help according to SIP } \\
\hline Total received help & & & 12 \\
\hline Changes in help & & & $9^{* *}$ \\
\hline Help totally implemented & & & 6 \\
\hline Help partially implemented & & & 3 \\
\hline \multicolumn{4}{|l|}{ Parallell interventions } \\
\hline Total social service and health care & 9 & 11 & \\
\hline Substance abuse (soc service) and addiction treatment (health care) & 6 & 4 & \\
\hline Mental health (soc service) and psychiatric care & 0 & 4 & \\
\hline Addiction (health care) and psychiatric health care & 1 & 0 & \\
\hline
\end{tabular}

${ }^{*}$ Several users had two or more interventions.

${ }^{* *}$ Number with any kind of change in interventions or help after coordinated plan. 
Table 3. Overview of participation in SIP.

\begin{tabular}{|c|c|c|}
\hline & & Total \\
\hline \multicolumn{3}{|l|}{ File } \\
\hline Substance abuse & 8 & \\
\hline Mental health & 3 & \\
\hline Child and family & 1 & 12 \\
\hline \multicolumn{3}{|l|}{ Number of SIPs } \\
\hline Four & 3 & \\
\hline Three & 1 & \\
\hline Two & 5 & \\
\hline One & 3 & \\
\hline Mean value & 2,2 & 12 \\
\hline \multicolumn{3}{|l|}{ Initiated SIP } \\
\hline \multicolumn{3}{|l|}{ Social service } \\
\hline Substance abuse - assessment & 4 & \\
\hline treatment providers & 0 & \\
\hline Mental health - assessment & 0 & \\
\hline care/support providers & 0 & \\
\hline \multicolumn{3}{|l|}{ Health care } \\
\hline Addiction treatment & 4 & \\
\hline Outpatient psychiatric care & 2 & \\
\hline Not documented & 2 & 12 \\
\hline \multicolumn{3}{|l|}{ Representation - social service } \\
\hline Substance abuse - assessment & 8 & \\
\hline treatment providers & 3 & \\
\hline Mental health - assessment & 3 & \\
\hline care/support providers & 3 & \\
\hline Child and family - assessment & 1 & \\
\hline Economic assistance & 1 & $19 *$ \\
\hline \multicolumn{3}{|l|}{ Representation - health care } \\
\hline Addiction treatment & 10 & \\
\hline Outpatient psychiatric care & 5 & \\
\hline Inpatient psychiatric care & 1 & \\
\hline Primary care & 0 & $16^{*}$ \\
\hline \multicolumn{3}{|l|}{ 0ther representation } \\
\hline Correctional probation & 1 & \\
\hline Social insurance & 0 & \\
\hline State employment service & 0 & 1 \\
\hline \multicolumn{3}{|l|}{ User participation } \\
\hline User participated & 12 & 12 \\
\hline Relative to user participated & 1 & 1 \\
\hline
\end{tabular}

only three cases in which both addiction treatment and psychiatric care participated. Other representation, from for example the social service's economic assistance, primary medical care, correctional probation, social insurance or the state employment agency, was found seldom or not all. (Table 3)

There were few SIPs in which all the relevant health care and social service agencies were represented. SIPs sometimes resulted in substantial changes in help and care, though many changes appeared to have been already planned, and other times in small adjustments or no changes at all.

For 10 of the 12 SIPs, follow-up meetings had been held. Time periods for follow-up varied from about one month to 12 months, with the longest periods concerning persons with mental health problems without concurrent substance abuse. Most follow-ups were planned, but in other cases it could be understood from journal entries that the follow-up was due to a change in the person's circumstances. Most follow-ups resulted in a new SIP, but though some included substantial changes, other new SIPs did not result in changes or only in what might be considered details ('home support three times a week' instead of twice, or 'possible adjustments in medicine dose'). 
It was not possible to determine how active the user had been or whether the user had been allowed to influence the interventions agreed upon. There was no file in which it was documented that the user had asked for a SIP. The standard form includes a box for the individual to 'approve information transfer' between organizations and in every case, it was documented that the user had been present at the meeting and in most cases the user had signed the SIP. But the SIPs themselves did not record the processes in the meeting and in most cases information in journal entries was limited to noting that the meeting had taken place. No trace was found in any of the files of the type of preparation in consultation with the user recommended by the Stockholm Region's manual (Stockholm Association of Local Authorities (KSL) and Stockholm County Council (SLL) 2014).

In many cases, the professionals who participated in the meeting did not have a mandate to make formal decisions about the interventions discussed. For example, addiction treatment was usually represented by a nurse, while the interventions discussed often concerned medicine, which can only be prescribed by a doctor. When interventions involving care outside of the home were discussed, those responsible for making the decision were often a political board, a doctor with the relevant mandate, or a court, none which were represented at SIP-meetings. In other cases, such as 'support in the home' from the social service, the responsible social welfare secretary was present at the meeting, but could only make the formal decision later. The formulations were sometimes short and concrete, but other times tentative, such as 'possible CBT-therapy' or 'consider 12-step treatment'.

Although specific information on how often SIPs were used was not gathered in this study, it was obvious that the frequency varied greatly between local authorities. Only one local authority had registered which files had a SIP, and the department could therefore inform the authors that they had 33 current SIPs. One of the local authorities which chose not to participate did so with the motivation that they had no SIPs at all.

\section{Analysis - collaboration and SIP in individual case documentation}

Documentation in the case files shows uneven use of SIP, with large variations between municipalities, and no specific motivation for SIP in individual cases. Problems were usually formulated simply as a list of needs and it was not possible for the authors to distinguish between immediate goals and interventions, as opposed to more long-term goals and planning. But the documentation also showed that, when SIP was used, the individual concerned did have a wide range of complex needs. Most users already had help from both the social service and either addiction treatment, psychiatric care or both. In most SIPs there were some changes in help, but there were often indications in the files that the new interventions were already planned or had actually started. Agreed upon interventions or help were in most cases wholly or partially implemented and follow-up meetings were usually held, either as planned or as a result of changed circumstances or difficulties in implementation of agreed upon interventions. There was little documentation of user participation in the SIP-meetings, other than that the user was present and had approved information transfer between the parts.

To analyse what kind of collaboration is indicated, the authors have used a characterization according to Andersson et al. (2011) scale. SIP can be seen as an 'interagency meeting', which is a model in the middle of the scale involving professionals from different organizations who meet to discuss individual clients or cases and agree on common activities. In the studies which Andersson and colleagues cite, interagency meetings may be more or less systematic. SIP appears to have been used very unsystematically. Meetings must be called only when there is a specific reason to do a SIP for a specific person and only professionals who are concerned with that particular individual are invited. The tendency in this study was that the agencies already involved or which most obviously could be expected to be involved by reason of the most immediate problems were those active in the SIP. The individual can ask for a SIP, but in 
this study no user had done so. This, of course, leaves the question of whether to do a SIP to the respective professional person's discretion. The other possibility according to Andersson and colleagues' scale is 'case coordination'. But the models for case coordination which Andersson and colleagues cite are commonly referred to as 'case management', which usually involves a professional person or a team which are defined specifically as case managers (Burns et al. 2001). In the cases in this study, the professional who had called the meeting had been designated only as responsible for coordinating the SIP, rather than having case coordination as a specific function.

To analyze what degree of collaboration is indicated, we may return once again to the theoretical model in Figure 2. According to this model, all meetings concerning an individual user occur along the horizontal axel. But to achieve a higher degree of collaboration, support is required from leadership levels along the vertical axel. With regard to SIP, the intention appears to be that support should be structured by the local collaboration agreements, the requirement for which, as we have seen, was enacted at the same time and according to the same proposition (Governmental Proposition 2008/09:193). Such agreements can be characterized as belonging to Andersson et al. (2011) category 'partnership', which is placed fairly high (third from the top) on their scale of collaboration forms.

In this study, a regional agreement provided the framework for such a structure. A regional coordinating council included representatives from the social service in the municipalities and from addiction treatment and psychiatric health care. In accordance with the regional agreement, the local agreements established local coordinating councils for second-tier managers, workgroups for front-line managers and provisions for SIP as a means of handling individual cases. However, the agreements motivated collaboration in a way which was somewhat diffuse and it is unclear whether the parts involved actually had the ambition to achieve collaboration in the sense of organizational integration. Much space was devoted to defining the respective organization's area of responsibility, which tends rather to clarify questions of 'coordination' between their respective operations than aim to effective collaboration (Axelsson and Bihari Axelsson 2006).

Nevertheless, the structure which had been built up could indicate a high degree of collaboration, were it not for the uncertain use on the level of the individual user. Even with reservation for differences which can be expected in legal requirements that are based on professional discretion, the variations found in this study appear to be surprisingly large. There were differences between local authorities in how often SIPs were done as well as which parts participated and representation from the respective parts. It should also be noted that these variations existed inspite of the availability of a manual published by the regional council.

The uneven use of SIP and the lack of mandate for some of the representatives in SIP-meetings show uncertain room for professional autonomy. These results indicate a fairly low to moderate level of contact between organizations and professionals on the horisontal axel, at the lowest organizational level of the vertical axel. This places SIP in a position $\mathrm{C} 2$, between positions CO and CI, somewhat closer to C0 (Figure 3). That is to say, SIP appears to have achieved a relatively low to moderate level of collaboration.

User participation is emphasized in the governmental proposition on SIP (Governmental Proposition 2008/09:193). Case file documentation, whether the SIPs themselves or other forms of documentation such as journal entries, can of course not be expected to show the full picture of what participation the individual has been allowed in meetings and discussions. Nevertheless, the role of the user appeared to be subordinated on the individual level, with more weight given to the role of the organizations.

In sum, the results indicate that SIPs in the study were primarily used to document short-term planning for the organizations and professionals involved. What's missing in the file documentation is the whole picture of the user's social and mental problems, and a long-term plan for rehabilitation in agreement with the user. 
Vertical integration Specialization $\mathrm{c}_{0}=$ No collaboration at all

$\mathrm{c}_{1}=$ Maximum collaboration concerning levels of decisionmaking and involvement between organisations

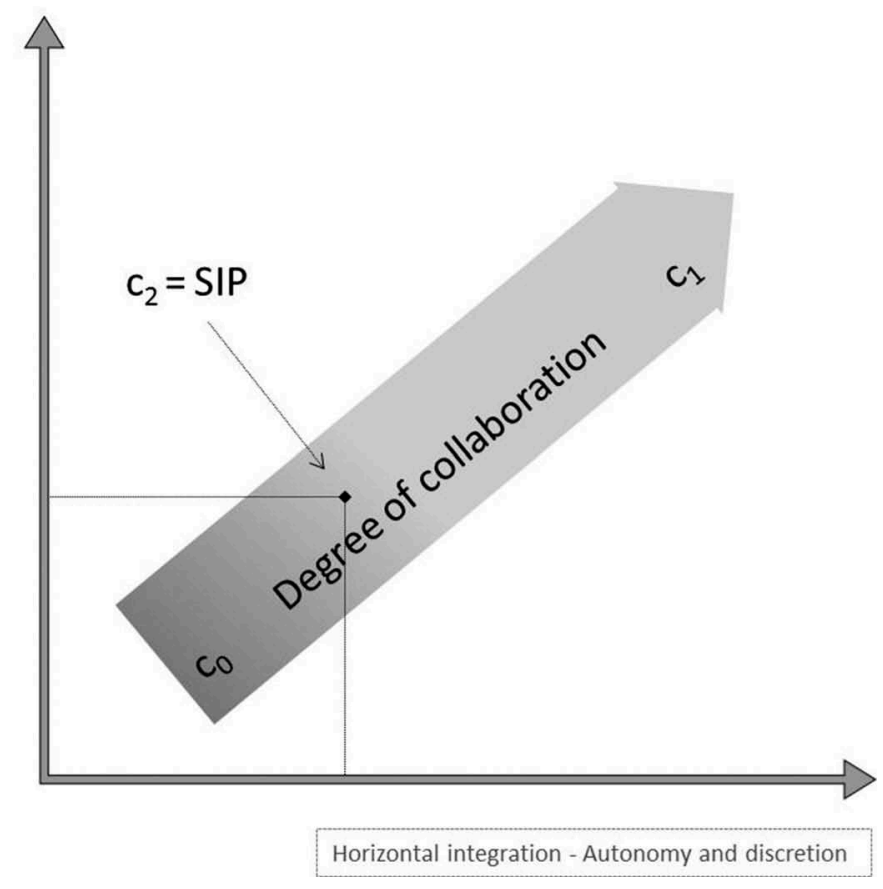

Figure 3. Degree of collaboration indicated by SIP documents and other case documentation.

\section{Discussion}

This study has aimed to explore explore collaboration in individual cases as it is indicated in SIPs and other case documentation, based on the questions of how SIP is motivated in individual cases, and what kind and degree of collaboration is indicated by the documentation. The authors have studied individual case files and found unclear motivation for SIP in specific cases, with no attempt to distinguish between short-term needs and long-term goals. The answer to the question of how collaboration is motivated, or 'why collaborate?' cannot be found in the documentation. The authors had expected to find formulations concerning why collaboration was necessary, for example that cooperation needed to be strengthened in order to plan for rehabilitation, that the individual had asked for a SIP, or that the individual's situation had worsened. These kinds of reasons may, of course, already have been understood by the professionals involved. It may also be noted that the standard form had no specific space for these kinds of formulations.

As to the kind of collaboration, the results for the study indicate that SIP can be characterized as an unsystematic form of interagency meeting, dependent on professional discretion and with an uncertain level of user involvement. The degree of collaboration indicated, as analyzed by the authors' interpretation of Axelsson and Bihari Axelsson's model of collaboration as a form of organizational integration (Figure 2), has been fairly low to moderate. Results showing uneven use of SIP are consistent with results from a survey evaluation in the region (Källmén and Elgán 2016) and an evaluation of SIP in another region (Winquist 2016).

On the regional level, initiatives have been taken to support local collaboration and there are agreements between the local authorities and their collaborative partners in the health care sector which have been reached in accordance with the regional agreement. It is uncertain, however, what level of ambition the parts which have signed the agreements actually have had. That is, whether they have aspired to effective collaboration or whether they would rather have been satisfied with a moderate level of coordination between interventions. 
In addition, the individual documentation raised the question whether most of the measures would have been decided even if a SIP had not been drawn up. The participants representing the various organizations often did not have a decision-making mandate and formal decisions could not be taken at the SIP-meetings. Neither was there any consistent way of categorizing long-term goals and problems as opposed to immediate problems more on a level of detail. SIPs can therefore further be preliminarily characterized as minutes from meetings concerning individual cases, with proposals for a wide variety of interventions which may or may not be carried out.

\section{Is SIP an optimal way to stimulate collaboration?- the need for continued research}

The authors have studied 12 individual case files. The data is further limited by the selective nature of case file documentation. Nevertheless, the case files have been studied thoroughly, reviewing both the SIPs and all other documentation. The results raise the question of whether SIP is an optimal way to stimulate collaboration for the target groups studied.

For a discussion of this question, it is necessary to consider these results in relation both to theoretical concepts, previous research on collaboration, and other aspects of the organizational and legal context in which SIP has been conceived and implemented.

The model shown in Figure 2 would indicate that a high level of collaboration requires maximum commitment on the horizontal axel in combination with maximum support and coordination on the vertical axel. In this study, the conditions required for position $\mathrm{C} 1$ in Figure 2, a high level of collaboration, appear to have been only partially achieved. SIP demands meetings and agreements among a wide range of professionals and organizations. That some of these have not been represented may be a rational response, since it may simply not be reasonable to attempt to regularly gather more than the most immediately concerned to a general meeting with respect to each individual. It may be, therefore, that the position $\mathrm{C} 1$ should be regarded as an ideal goal which can be difficult to achieve in real world situations.

Furthermore, it appears that organizational structures are needed which support and provide opportunities for necessary collaborative processes. As do other authors, Andersson et al. (2011) discuss barriers and facilitators for collaboration, often described as 'two sides of the same coin'. Examples are communication, which may be better or worse; trust, which takes time to build up but can be quickly destroyed; and territoriality, for which the opposite is 'common ground'. Axelsson and Bihari Axelsson (2006) demonstrate that processes between the collaborating parties are necessary to overcome such barriers, using the example of a 'forming-norming-storming-performing' process which may occur in multi-disciplinary teams. If several organizations are involved, as is often the case with complex needs, the difficulties multiply (Matscheck and Fleetwood 2013). If a customer choice system is used, several or many service providers can be involved, further increasing complexity.

In Matscheck and Axelsson's study (2012,) a local collaboration agreement was the formal basis for a complex local structure which created arenas for collaboration processes to develop. Matscheck and Axelsson argue that, to achieve successful collaboration, it is necessary for every level of each organization to cooperate horizontally with the corresponding vertical level of the other organizations. To do this, it is necessary to motivate and interest personnel (see for example Hill and Hupe 2014). Otherwise, one may be left with a top-down model which achieves only partial implementation and thereby a position in Figure 2 which is closer to $\mathrm{C} 0$ than to $\mathrm{CI}-$ that is, the position which the results in this study indicate.

In Matscheck and Axelsson's (2012) study, the collaborative structure provided 'arenas' where more or less intensive processes could take place, always involving direct contact and dialogue to improve communication and build trust. This picture suggests that SIP may provide such an 'arena for contact' on the individual case level, but more for discussion of expected or already implemented interventions than a widening of perspective. In this way, SIP may provide opportunities for the kinds of processes which are necessary for successful collaboration. 
Another question which deserves further attention is how regional and local collaboration agreements can best be formed to provide supporting structures. In this study, there existed regional and local agreements, but the motivation for collaboration formulated in the agreements could be described as diffuse. In the regional agreement, much focus was instead placed on Evidence-based Practice (EBP) and other aspects of quality and development (Matscheck and Fleetwood 2013). The local agreements seemed rather to stress coordination which, as indicated in Figure 2, is a more limited ambition than actual collaboration, which is a synthesis of the vertical axel with contacts on the horizontal axel. Defining areas of responsibility is naturally a necessary basis for contacts and meets legal requirements for such agreements, but does not in itself advance deeper integration which can be termed as collaboration.

The laws which regulate SIP, the Social Service Act and the Health and Medical Care Services Act, are both what in Swedish are called 'framework laws' (Swedish 'ramlagar'). 'Framework laws' are defined as 'laws which stipulate the general goals of the legislation and leave more detailed regulation to the relevant authorities' (Hetzler 1991, author's translation). This means that specific use of SIP must be determined by the professional discretion of the social workers and health care professional involved in each individual case.

In some ways, however, the legal requirements for SIP are actually fairly specific. A coordinated individual plan ('SIP') must be drawn up when the local authority or the county council makes the judgement that it is needed and when the individual gives his/her consent. The plan shall specify which services are needed, which services each authority is responsible for, which interventions other authorities are responsible for, and which authority has overall responsibility for the plan (SFS 2001:453, amended 2009:981). The obligation to do a SIP is far-reaching and in the governmental proposition persons with mental health illness and concurrent substance abuse are particularly pointed out as group for whom the norm should be that a SIP is needed. The possibility for the user to ask for a SIP is also specified (Governmental Proposition 2008/09:193).

It is possible that professional discretion is a more correct explanation for the uneven use of SIP than the authors' suggestion of inadequate structure and collaborative processes. That is, that some professionals see the need for SIP more often than others, or that the need for SIPs varies between local authorities and units of operation. Nevertheless, the results of this study show a tendency to formalization. Nearly all of the SIPs in the study used a form provided by the county council's health care organization. Thereby, they followed the same headings, which would encourage the tendency to use SIP in similar ways. The use of a standard form has made it possible for the authors to accumulate quantitative data in the study. In the future, the leadership in the local authorities and health care providers may attempt to improve the form by adding spaces for motivations and distinctions between short-term goals and long-term planning. In response, professionals may informally develop a set of standard formulations, thereby leading to increased formalization.

A preliminary conclusion is that SIP is probably less effective for collaboration than stronger and more distinct models such as case management or multidisciplinary teams, which are directed specifically to those users whose needs require not only coordinated but integrated interventions. The authors expect that such models also would require organizational support on the vertical axel in Figure 2 in order to achieve implementation along the horizontal axel, that is to say, genuine collaboration.

Although quantitative results which can be tested meaningfully for significance naturally must wait for a larger study, this explorative study made one question regarding methodology abundantly clear. There appears to be no possibility to, by means of a file study, evaluate specific effects of collaboration with acceptable validity, with or without SIP. The cases involved have many similarities but also differences regarding problems and needs, actors involved, time periods and other factors which prohibit necessary stringency. One of the underlying reasons for these variations is the professional discretion discussed above, which steers the use both of SIP and 
other forms of formal or informal collaboration, regardless of policy recommendations or collaboration agreements. But it is also a fundamental problem for attempts to measure collaboration in areas such as mental health and substance abuse that there are so many individual variations, particularly when the collaboration attempts to cover the person's total situation including both medical and social aspects. Nevertheless, the authors have found that the files, in combination with the regional och local collaboration agreements, have yielded large amounts of material for fruitful study of collaboration.

The findings related here can be viewed only as indications of various tendencies, pending results from larger studies and follow-up studies involving, for example, interviews based on file study results. The authors have hoped that our explorative study would raise further questions and some have been identified. Another such question has to do with the effects of New Public Management (NPM) on collaboration. There are some indications in this study of how NPM affects SIPs, particularly the purchaser-provider split. The specialized health care agencies represented were care providers, while the social service was primarily represented by purchasers. This meant that the representatives for the specialized health care often worked directly with the user, while the social service representatives were mostly concerned with determining assignments for providers, whether operated by the social service or privately. What this distinction results in for the user needs to be investigated further.

Another question is whether SIP leads to increased user participation. With reservation for the inadequacy of case file studies as a method for examining processes of user participation in meetings, the documentation of user participation in this study seems surprisingly low, inspite of the guidance provided by a regional manual which stressed user participation.

A final and overarching question is whether the legislation in Sweden, with its combination of collaboration agreements on a structural level and SIP on the individual level, can lead to beneficial effects for users, or whether inadequate organizational support and other factors will stand in the way.

\section{Notes}

1. Representatives from other agencies, such as the state employment service or the state social insurance, may be invited to participate. A new version of the regional agreement has retained the original structure (Stockholm Association of Local Authorities and Stockholm County Council 2016).

2. Second-tier managers are defined here as having personnel and budgetary responsibility for their units, as opposed to front-line managers who are mainly responsible for work supervision (Shanks, Lundström, and Wiklund 2015).

\section{Disclosure statement}

This article is based on a collaborative project between the Institution for Social Work at Stockholm University and FoU-Nordväst (RD Northwest), which is a joint research and development unit funded by eight local authorities.

\section{Funding}

The project was completed within existing resources, i.e. without special funding. The authors would like to thank the local authorities for their cooperation.

\section{References}

Andersson, J., B. Ahgren, S. Bihari Axelsson, A. Eriksson, and R. Axelsson. 2011. "Organizational Approaches to Collaboration in Vocational Rehabilitation - An International Literature Review." International Journal of Integrated Care 11 (October-December). 
Axelsson, R., and S. Bihari Axelsson. 2006. "Integration and Collaboration in Public Health - A Conceptual Framework." International Journal of Health Planning and Management 21 (1): 75-88.

Billquist, L., and L. Johnsson. 2007. "Sociala akter som empiri. Om möjligheter och svårigheter med att använda socialarbetares dokumentation i forskningssyfte [Social Case Files as Empirical Data. On the Possibilities and Difficulties with Using Social Workers' Documentation in Research].” Socialvetenskaplig Tidskrift 1: 3-19.

Burns, T., A. Fioretti, F. Holloway, U. Malm, and W. Rössler. 2001. "Case Management and Assertive Community Treatment in Europe.” Psychiatric Services 52 (5): 631-636. doi:10.1176/appi.ps.52.5.631.

Drake, R. E., S. M. Essock, A. Shaner, K. B. Carey, K. Minkoff, L. Kola, D. Lynde, F. C. Osher, R. E. Clarke, and L. Richards. 2001. "Implementing Dual Diagnosis Services for Clients with Severe Mental Illness." Psychiatric Services 52 (4): 469-476. doi:10.1176/appi.ps.52.4.469.

Ekendahl, M., and P. Karlsson. 2013. Brukarnöjdhet $i$ beroendevården - En studie av patientinflytande, behandlingstilltro och samordnade insatser [User Satisfaction in Addiction Treatment - A Study of Patient Influence, Trust in Treatment and Coordinated Interventions]. Stockholm: Stockholms stad.

Governmental Proposition 2008/09:193. Regeringens Proposition - Vissa psykiatrifrågor m.m. [The Swedish Government's Proposition - Certain Questions Concerning Psychiatry etc.].

Hetzler, A. 1991. "Ramlagar, rätten och politiken [Framework Laws, Law and Policy].” Tidskrift För Rättssociologi 7-8: 248-272.

Hill, M., and P. Hupe. 2014. Implementing Public Policy. London: Sage.

Hood, C. 1991. A Public Management for All Seasons. London: Blackwell.

Horsfall, J., M. Cleary, G. E. Hunt, and G. Walter. 2009. "Psychosocial Treatments for People with Co-Occurring Severe Mental Illness and Substance Use Disorders (Double Diagnosis): A Review of Empirical Evidence." Harvard Review of Psychiatry 17 (1): 24-34. doi:10.1080/10673220902724599.

Källmén, H., and T. Elgán 2016. Samordnad Individuell Plan (SIP) - En uppföljande studie av en utbildningsinsats till personal inom Stockholms län [Coordinated Individual Plan - A Follow-Up Study of a Training Program for Personnel in the Stockholm Region]. Rapport nr. 59. Stockholm: STAD.

Lawrence, P. A., and J. W. Lorsch. 1967. Organization and Environment: Managing Differentiation and Integration. Boston: Harvard University Press.

Lindberg, K., and E. Wikström. 2013. “Samverkan i missbrukarvården - Komplexa projekt och ansvarsredogörelser [Collaboration in Substance Abuse Care - Complex Projects and Statements of Responsibility]." In Om Samverkan - för utveckling av hälsa och välfärd [On Collaboration - For Development of Health and Welfare\}, edited by R. Axelsson and S. Bihari Axelsson. Lund: Studentlitteratur.

Matscheck, D., and R. Axelsson. 2012. “Arenas for Contact.” Scandinavian Journal of Public Administration 16 (2): 93-113.

Matscheck, D., and C. Fleetwood. 2013. "Samverkan inom missbruk och beroende [Collaboration in Substance Abuse and Addiction]." In Om samverkan - för utveckling av hälsa och välfärd [On Collaboration - For Development of Health and Welfare\}., edited by R. Axelsson and S. Bihari Axelsson. Lund: Studentlitteratur.

Melke, A. 2010. Mental Health Policy and the Welfare State. Diss. Gothenburg: School of Public Administration. University of Gothenburg.

Merriam, S. 1988. Case Study Research in Education. San Francisco: Josey-Bass.

Miller, C., and Y. Ahmad. 2000. "Collaboration and Partnership: An Effective Response to Complexity and Fragmentation or a Solution Built on Sand?” International Journal of Sociology and Social Policy 20: 1-38. doi:10.1108/01443330010789151.

National Board of Health and Welfare [Socialstyrelsen]. 2011. "Nationella riktlinjer för psykosociala insatser vid schizofreni och schizofreniliknande tillstånd." [The National Guidelines for Psychosocial Interventions for Schizophrenia or Schizophrenia-Type Conditions 2011]. Stockholm: Socialstyrelsen.

National Board of Health and Welfare [Socialstyrelsen]. 2015. "Nationella riktlinjer för vård och stöd vid missbruk och beroende." [The National Guidelines for Care and Support for Substance Abuse and Addiction]. Stockholm: Socialstyrelsen.

Scott, J. 1990. A Matter of Record. Cambridge: Polity Press.

SFS.1982."763 Hälso- och sjukvårdslagen [Swedish Code of Statutes 1982:763." Health and Medical Care Services Act].Amended 2009:979, 2013:302. SFS.

SFS 2001:453. Socialtjänstlagen [Swedish Code of Statutes 2001:453. Social Service Act.] Amended SFS 2003:407, SFS 2003:412, SFS 2009:981, SFS 2013:303.

Shanks, E., T. Lundström, and S. Wiklund. 2015. "Middle Managers in Social Work. Professional Identity and Management in a Marketized Welfare State." British Journal of Social Work 45: 443-460. doi:10.1093/bjsw/bcu061.

Stockholm Association of Local Authorities (KSL) and Stockholm County Council (SLL) [Kommunförbundet i Stockholms län och Stockholms läns landsting]. 2014. "Samordnad Individuell Plan (SIP) för vuxna och äldre i Stockholms län Vägledning för personal i kommuner och landsting." [Coordinated Individual Plan (SIP) for Adults and Elders in Stockholm County - A Manual for Personnel in Local Authorities and the County Council]. Stockholm: KSL and SLL.

Stockholm Association of Local Authorities (KSL) and Stockholm County Council (SLL) [Stockholms Läns Landsting och Kommunerna i Stockholms län]. 2016. Samverkan kring personer med missbruk/beroende - 
överenskommelse mellan Stockholms läns landsting och kommunerna i Stockholms län [Collaboration around persons with substance abuse/addiction - formal agreement between the Stockholm County Council and the Local Authorities in the Stockholm Region]

Sullivan, H., and C. Skelcher. 2002. Working across Boundaries - Collaboration in Public Services. Basingstoke: Palgrave MacMillan.

Winquist, M. 2016. Uppföljning av arbetet med Samordnad Individuell Plan $i$ Uppsala Län [Follow-Up of Implementation Work with Coordinated Individual Plan in the Uppsala Region]. FoU-rapport 2016/1, Uppsala: Regionförbundet Uppsala län. 